\title{
Study on the Factors of Physical Deterioration and Improving Measures of Contemporary College Students
}

\author{
Zhou Haibo ${ }^{1,2, a}$, Sun Daming 3,b* \\ ${ }^{l}$ Department of Physical Education, Guangzhou Huashang University, Zengcheng District, Guangzhou, Guangdong, \\ China \\ ${ }^{2}$ Graduate University of Mongolia, Ulan Bator, Mongolia \\ ${ }^{3}$ Graduate School of Wuhan University of Physical Education, Hongshan District, Wuhan, Hubei, China \\ 1433971902@qq.com \\ b1016122799@qq.com
}

\begin{abstract}
The youth is strong, our country from the sports power step into the era of sports power, good physique is a strong vitality of a country, but also the pace of contemporary society forward. Today, the contemporary university students physique status decline year by year is not optimistic, students of physical decline in a range of issues worthy of our thought, based on the factors of family education, social development factors, students' own factors and carry on the omni-directional, school education factors of contemporary university students' physical constitution in the related issues of research, In addition, scientific and reasonable measures are proposed to find the problems related to the decline of the physical fitness of college students. Based on this, the relevant measures to improve the physical fitness of students in a scientific and reasonable way are mainly based on family education and parents' physical practice to correctly guide the concept of sports. To develop the dominance of campus associations and cultivate students' awareness of extra-curricular physical exercise. Physical education to cultivate students not afraid of hardship and tired sportsmanship, the school strictly grasp the quality in the process of physical education. Its main purpose is to arouse the attention of society, schools and related departments to the physical fitness of college students, and to provide scientific theoretical basis for effectively improving the physical fitness of college students.
\end{abstract}

Keywords: Student constitution, Physical decline, Sliding factor, Strategy research

\section{当代高校学生体质下滑因素及提高措施研究}

\author{
周海波 ${ }^{1,2, \mathrm{a}}$ 孙大明 ${ }^{3, \mathrm{~b}} *$ \\ ${ }^{1}$ 广州华商学院体育教学部, 增城区, 广州, 广东, 中国 \\ 2 蒙古国研究生大学, 乌兰巴托, 蒙古国 \\ ${ }^{3}$ 武汉体育学院研究生院, 洪山区, 武汉, 湖北, 中国 \\ a1433971902@qq.com \\ b1016122799@qq.com
}

摘要：少年强则国强，我们国家由体育大国足步迈进体育强国的时代，良好的体质是一个国家强有生命力的 体现，同时也是当代社会前进的步伐。如今，当代高校学生体质现状逐年下滑不容乐观，大学生们体质下滑的 一系列问题值得我们深思，本文基于家庭教育的因素、社会发展的因素、学生自身的因素以及学校教育的因素 进行全方位的深入剖析, 对当代高校大学生身体体质呈现下滑的相关问题开展研究, 并对发现大学生身体体质 下滑的相关问题提出科学合理的措施, 基于此, 科学合理提升学生体质状况的相关措施主要以家庭教育家长要 身体力行, 正确引导体育观念。开发校园社团主导性, 培养学生课外体育锻炼的意识。体育教学中以培养学生 不怕苦与累的体育精神为主, 学校严格把握体育教学过程中的质量关。其主要宗旨还是引起社会、学校及有关 
部门对大学生身体体质问题的关注, 为有效提升大学生身体体质水平提出科学的理论依据。

关键词: 学生体质, 体质下滑, 下滑因素, 策略研究

\section{1. 前言}

我国已入了全球经济大国范围, 目前我国的经济 一直处于稳定发展的趋势、国民的经济收入持续增加, 但是，我国广大青少年体质下滑情况逐年加剧。广大 青少年身体体质状况对当今和未来都产生双重的影 响, 甚至会对我们国家整体综合实力的发展带来不利 的一面。现如今, 关于大学生体质健康现状的研究自 2002 年 《学生体质健康标准》的试行以来 ${ }^{\left[{ }^{11}\right.}$, 经过 研究分析很多大学生体质健康未达到标准, 主要体现 在大学生们的肺活量持续下滑趋势, 50 米短跑以及 800 米与 1000 米中长跑速度与耐力明显下滑, 引体 向上与立定跳远其上肢下肢爆发力也是明显的下降, 大学的体重肥胖率持续增长, 高校大学生视力发生近 视率依然是呈现逐年上升的趋向。广大高校大学生体 能以及身体素质方面每年都会有所下降, 主要还是由 于缺乏长期的体力劳动以及体育运动导致的。我国面 对广大学生身体体质问题其形势依然不乐观。习近平 总书记在北京考察冬奥会场馆和观摩运动员训练时 就有所强调, 中国未来发展成为一个强国, 在各方面 发展都要强, 学生强则中国强, 体育强则中国强, 这 也是更好地促进我国体育事业蓬勃发展。

\section{2. 高校学生体质下滑的相关因素}

\section{1. 家庭教育的因素}

1980 年我国开始提倡晚婚晚育优生优育的政策, 实行一个家庭生一个子女的计划生育政策, 目前, 我 国高校大学生多数出生为独生子女家庭, 这样的家庭 模式使子女得到父母们的关注与宠爱不断增加, 因此, 很多独生子女生活能力基本上都是父母一手安排, 同 时也就逐渐养成了依赖父母的心理, 从而, 一些简单 的体力家务都是由父母们去做, 缺乏一种体力锻炼, 导致学生们产生懒惰的意识, 完全接受不了生活中的 一丁点苦与累。父母是子女们最好的老师, 家庭是子 女的第一所学校 ${ }^{21}$, 又是一切教育的源泉。体育教育 观念也是家庭教育非常重要的一部分, 理应引起家长 们认知与重视, 然而, 在我们现实生活中并不是这样 发展的, 大部分家庭中父母觉得万般皆下品惟有读书 高的理念灌输给子女, 利用周末以及节假日参加各种 文化课学习补习班, 唯独体育补习班安排的少, 一味 地去追求名校、获得高学历取得博士学位, 对子女成
龙成风的期望值过高。从而导致了大部分独身子女对 体育项目的误解, 缺乏体育知识的了解和参加体育活 动的锻炼。再加上很多父母为了还没的各种补习班学 费以及家庭生活开支不得不把大量时间投入在工作 中, 父母陪伴子女参与体育锻炼的时间少之又少, 由 于父母只关注孩子们的学习成绩, 认为能吃能喝没啥 毛病就是健康的标准, 正是由于这样错误的认识, 导 致每年大学新生开学许多大学生军训都不能按时完 成训练科目, 运动会项目不敢参加报名, 甚至体能测 试项目都及格不了, 由此可见, 父母在关注子女们文 化学习的同时, 对参加体育锻炼也要保持正确的理解, 更要落实在客观行动上。这也是对子女未来的身体健 康营造良好的氛围。

\section{2. 社会发展的因素}

随着人类文明的不断飞跃发展, 科学技术的迅速 腾飞, 各种大数据以及人工智能时代趋势尤为显著, 我们逐步迈入了信息化时代的步伐。现在的社会生产 方式和生活方式与以往的相比简直是翻天覆地的化, 随着高科技智能产品的不断涌现, 我们的生活节奏加 快了前进的步骤, 在生活与物质上面得到了有效改善, 但是, 许多高校学生渐渐地依赖于这些智能产品, 从 而缺乏了体力劳动的参与, 也渐渐引发了许多身体体 质下滑的问题，例如 “亚健康”、“肥胖症”、“体质不 达标” 等相关问题引人注目。最近几年来, 我国高校 生源也在逐年增加, 从而引起部分大学生毕业面临着 找工作难, 社会发展所带来的岗位竞争也愈演愈烈, 当今的高校大学生要面临找工作、考研、考证等压力, 而顺利毕业与找到对口合适的就业岗位一直是大学 生最大的压力, 为了寻找更好的就业岗位, 其思想也 产生了诸多想法, 因此, 同学们也面临着思想与心理 的双重压力。要学的知识与考证的相对较多, 从而导 致了每周除了上体育课以外再无其它体育锻炼活动 的时间, 课余身体锻炼时间明显压缩, 因而导致严重 的作息不规律、思想高度紧张等, 这可能也是导致大 学生身体体质下滑的一个关键性因素。无形中给学生 体质健康水平的下降埋下了隐患 ${ }^{\mathbf{3}}$ 。

\section{3. 学生自身的因素}

我国正处于大数据信息化时代, 各种智能产品层 出不穷, 目前, 高校大学生人手一部手机, 大约 90\% 的大学生又拥有一台电脑, 这些智能产品给同学们学 
习文化知识带来了便捷，但是，依然会有一部分学生 对手机以及电脑产生过度依赖性。例如: 同学们使用 手机点外卖, 课下往上购物等等, 这样就会占据大学 生们的大量的学习时间, 直接导致同学们课余活动的 空间逐步减少, 对学生的身体健康产生了消极的影响 [4]。由于每个人的生活规律以及饮食习惯不同，所表 现出来的体质也不尽相同，根据调查显示，大约 $60 \%$ 的学生没有吃早餐的习惯, 饮食不规律的学生大约占 $50 \%, 90 \%$ 的学生对甜品饮料以及碳酸饮料感兴趣, 这 些状况将会诱发一些低血糖以及身体肥胖等, 还会影 响同学们的学习成绩。再加上大部分学生都会有经常 謷夜的习惯，没有规律的作息时间，很容易导致身体 免疫功能下降, 影响身体体质的良好发展。当然, 一 些学生会有攀比的心理, 他们会产生抽烟、酗酒等坏 习惯, 不良的社会习惯影响学生的身心发展 ${ }^{[51}$, 这也 是影响学生体质健康下降的新因素。

\section{4. 学校教育的因素}

改革开放以后, 特别是在实施科教兴国战略以来, 我国的高等教育工作有了明显的成就。但是, 也有体 育研究者认为: “学校体育的相对滞后是导致大学生 身体素质下降的主要原因” ${ }^{6}{ }_{6}$ 。体育与教育应是共同 发展的, 提倡体育与教育融合的新型发展形式, 不管 怎么说, 体育教育也是教育的一个重要分支, 但是在 现实的生活中, 部分学校由于各种因素的限制学校体 育教育并没有更好的发挥出它的价值功能。由于有些 学校学生一直有追求高学历高学位的思想观念, 从而 造成缺乏学生主动参与体育锻炼的意, 这也是导致大 学们的身体素质下降的原因。久而久之, 体育科目以 及体育运动会处于不受重视的边缘学科, 甚至有些学 校对体育科目的投入力度不够, 偏远地区的学校没有 标准的塑胶田径场以及体育器材的严重不足, 无法有 效满足学生的体育运动的需求, 部分学校把体育课当 做安全教育课来对待, 以学生的安全第一为主位, 从 而导致体育课渐渐地失去了身体对抗、竞争的功能价 值, 这样的情况下学校体育想要达到国家标准值是无 法完成的。由于部分高校学生在中小学阶段没有自律 性的体育习惯, 因此, 也未形成对体育锻炼行为的重 视意识 ${ }^{[71}$, 也就没有取得有效的体育教育。这也是在 校大学生们消极对待体育课因素之一, 基于此, 院校 相关领导和体育部门教师对体育科目做出合理规划, 慎重对待体育教学的良好发展。

\section{3. 提升学生体质状况的相关措施}

\section{1. 家庭教育家长要身体力行, 正确引导体育 观念}

家长要树立全面的发展观并具有榜样的大局观。 父母是孩子最好的老师, 家庭教育是一切教育的源泉, 学校体育教育能否有序发展也需要广大家庭合理支 持和共同促进。因此, 家长们要身体力行积极的加入 到身体锻炼队伍，最好和孩子们一起加入体育队伍中，
这样以便学生在学校和家庭都能感受到体育锻炼带 来的欢乐与重要性。党的十八大再次提出 “落实立德 树人，促进德智体美全面发展” 的教育方针。家庭教 育中家长是学生生活学习之中的指导者, 家长的一言 一行以及思想观念都会深深的影响着学生发展方向。 强烈呼吁广大学生家长体育教育还要从小学生时代 开始抓起, 培养孩子定期参与体育运动, 树立终身体 育的思想, 要向阳关体育、健康体育、促进德智体美 全面发展方向为出发点, 言而总之, 学生身体体质的 有效提高是当前急需解决的难题, 有效把握难题的导 向, 才是合理有效解决难题的前提。认真学习国家相 关政策的科学导向性、严格把握学校体育教学工作尺 度、充分地调动家长身体力行的榜样性作用, 从而有 效结合了国家政策、学校、家庭三方面的协同发展, 有效促进学生身体体质的健康效应, 而且, 全国亿万 青少年体质健康促进的难题, 也将逐渐能够得以解决 ז81

\section{2. 积极开展校园社团主导性, 培养学生课外 体育铦炼的意识}

学校是有效开展体育教育活动的良好场所, 有着 独特的氛围, 学校的体育社团是由学生自发性组织与 服务学生的, 在学校大环境中逐渐发展成熟, 学校体 育社团所面对的对象是学生, 其性质和社会上的体育 团体活动不相同。在平时的生活中学生可以根据自己 的兴趣选择喜欢的体育社团项目, 从而培养学生课余 体育锻炼的意识。进而引起同学们对体育运动的兴趣, 使学生能够在心理上获得满足感和成就感。高校学生 可以利用学校体育社团平台经常性的参加一些有利 于身心健康发展的活动比赛, 以便有效加强体育锻炼 与提升自身身体素质, 学校部门可以通过海报宣传以 及体育课堂宣讲会进行适当引导, 为校园体育良性开 展打下浓厚的气氛, 在大学生们心中无形的树立了参 与体育活动的观念、学会以及了解某些体育项目, 同 时通过体育课教学和同学们主动参与体育社团活动 所带来的乐趣, 对进一步培养学生不怕吃苦、敢于迎 难而上的意志具有促进作用, 学校的体育社团在校园 活动中相对比较活跃, 以丰富多彩的内容和多种多样 的活动形式积极开展校园体育社团的主动性, 让更多 的大学生主动地加入到体育活动的行列。

\section{3. 体育教学中以培养学生不怕苦与累的体 育精神为主}

任何一所学校的体育教学目标要以培养学生身 体 “健康第一” 为指导原则, 树立 “终身体育” 为指 导思想, 体育教学中主要以身体对抗以及身体素质训 练为目的, 这时人体各器官与肌肉系统也在不停地加 快代谢, 会消耗很多能量, 体内的代谢过多将会导致 身体不同状况的疲劳, 这也许就是同学们所说的体育 运动的 “苦和累”, 主要体现在心跳加速、大量排汗、 身体疲㛀等。但在短暂的休息之后体力将会逐渐恢复, 
并不会影响人体的康，反而会提高身体素质。因此， 在体育课教学过程应该把握好适宜的运用量, 随着 同学们年龄增长以及身体体质的改善, 在一定的情况 下可以循序渐进合理增加体育课运动负荷量, 这对有 效提高学生身体体质、学会运动技能、了解体育健康 常识都具有重要意义。所以说, 身体运动所产生的疲 劳状态是正常的生理现象, 并不会妨碍我们的学习与 生活, 而且以这种运动产生的疲甾现象作为参照物, 体育教学中学生锻炼有必要达到某种特定的疲劳状 态，才能获得超量恢复的效果，只有经过坚持到底、 长年累月的锻炼, 我们的身体体质将会逐步达到国 家体质标准值范围。正所谓, 量变必然引起质变。当 然也要重视学校的体育设施的投入与管理, 给同学们 创造良好的学校体育气氛。把 “健康第一”、“终身 体育” 作为学校体育工作首要任务, 这也是有效发展 学校体育工作的有效途径。

\section{4. 学校严格把握体育课过程中的质量关}

强化学校的体育课要落地有声。《中共中央关于 全面深化改革若干重大问题的决定》中明确提出: “强 化体育课和课外锻炼, 促进青少年身心健康、体魄强 健 ${ }^{91}$ 。” 如何更好的实施文件要求? 主要问题还是要 严格把握学校体育课的质量, 在体育课堂上要强化每 一节课的互动性意识, 同时还要体育教师们采用灵活 多变的教学方法以便有效提高同学们学习的兴趣, 可 以采取以国家大学生体质达标值进行针对性的教学, 并根据体质测试的项目引进体育课堂, 把体侧内容与 体育教学有效结合, 以强化学生身体体质为主。让全 体学生的身心发展与体质体能都可以得到锻炼。当然, 想要达到一定程度的上的锻炼效果, 第一, 还需要加 强教师队伍的建设以及重视教师外出进修培训, 引进 教学名师和专业人才从而科学地开展高质量的体育 教学活动。第二, 学校可以开展早操活动, 学校的体 育场馆在早上 6 点开放方便同学们去锻炼自己喜欢 的体育项目, 每周固定有两个下午不排文化课, 让同 学们在这样的课外时间进行体育锻炼培养体育兴趣, 向每天 2 个小时的体育锻炼看齐, 为巩固和强化学生 学习运动技能、身体体质达标以及终身体育思想奠定 基础, 总的来说, 学校严格把握体育课过程中的质量 关, 注重全体学生参与体育锻炼、全体学生受益体育 带来的健康与快乐, 为有效促进学生的身心健康成长 与良好的体质发展打下基础。

\section{作者简介:}

周海波, 男, 广州华商学院体育教学部, 讲师, 在读 博士研究生, 1433971902@qq.com, 教育学 (体育教 育）研究方向。

\section{REFERENCES}

[1] Hu Yi. (2019) Analysis on the Current Situation and Countermeasures of Students' Physical Health in
Hunan University of Technology under the Background of Healthy China D. Hunan University of Technology,

[2] Zhang Honglin. (2019) Optimizing Family Education and Promoting Middle School Students' Moral Character J. Modern Vocational Education, pp220-P221.

[3] Liang Shuai. (2011), Reasons and Countermeasures for the Decline of Physical Health Level of College Students J. Journal of Xinzhou Normal University,pp41- 43.

[4] Deng Jiexin. (2018) Investigation on the Status Quo of Post-school Physical Activities of Non-PE Undergraduates in Universities in Xinxiang City J. Movement,pp59- 60.

[5] Huang Ping, Xue Yangguang. (2018) Reasons and Countermeasures of Students' Physical Health Decline J. Youth Sports,pp105- 106.

[6] Wang Huimin. (2016) Reflections on the reasons for the physical decline of college students J. Contemporary Sports Technology, pp86- 87.

[7] Wang Zhiqin. (2018) Research on Factors Influencing College Students' Physical Exercise Behavior and Self-management Effect J. Science and Education Guide, pp186- 187.

[8] Wang Xianying. (2016) Difficulties and synergistic promotion strategies for students' physical health enhancement J. Journal of Physical Education, pp112- 115 .

[9] Liu Haiyuan. Tang Jiping, (2014) Discussion on Implementing the Spirit of "Strengthening Physical Education Class and Extracurricular Exercise" J. Journal of Chengdu Institute of Physical Education, pp1- 7 . 